\title{
CROWDFUNDING GETS CONQUERED BY VENTURE CAPITAL
}

\author{
Zoran Ćirić163 \\ Stojan Ivanišević ${ }^{164}$ \\ Otilija Sedlak ${ }^{165}$
}

https://doi.org/10.31410/itema.2018.399

\begin{abstract}
Initial Coin offerings represent an alternative method of fundraising for projects that do not require established reputation, working project, interaction with banks for raising capital, etc. It uses crowdfunding instead ICO's, that represents a financing model which enables everyone with internet and enough money to invest regardless of its country of residence or any other attribute. ICO essentially represents an invention that enables any startup company to fund itself without any equity obligation or commitment. These attributes allowed startup companies to gather necessary finding via crowdfunding from multiple sources around the globe. Since the funding process is usually built with blockchain network (ETH Blockchain is the predominant one) tracking of the smart contracts and contribution can allow a higher degree of insight into the funding process because it is completely transparent. Analyzing this data can provide insight into the number of participants and contributed amount. The goal of this research is to see are the ICO-s found by a large number of small investors by crowdfunding process or Venture Capital (VC) are predominant investors and what is the exact ratio of small investors compared to large capital institutions and investors. The primary data source is Etherscan (www.etherscan.io). The goal of this paper is to make an overview of ICO financing and starting point for further trend tracking. These results will aid the researchers and startups doing the ICO's to prepare the investment and marketing strategy for their projects in order to gather their funding in a more efficient manner.
\end{abstract}

Keywords: Crowdfunding, Venture capital, ICO, Blockchain, distribution

\section{INTRODUCTION}

nyone with Internet can be an investor into the ICO and investment can be made from $\mathrm{A}$ any personal computer or smartphone without any legal or paper procedure. This lack of legal framework regarding the ICO process works both ways so participants do not go through demanding legal procedures and absence of financial market institutions such as brokers, custodians, registers etc; Startup companies that are making ICO's do not require any legal paperwork for gathering capital that is usually required in their domicile countries. Unlike standard investment process companies seeking funding via ICO do not require working product, good track record, good financial data, only an idea is required. This represents a double-edged sword - lack of due diligence and regulation caused loss for many investors both institutional and individual. Government regulators are creating legal and institutional frameworks to solve these problems and regulate ICO market so to call it. The main research area of this paper is to analyze a number of contributors and contribution amount and relative percentage in total raised money into the ICO's in order to separate small investors

\footnotetext{
${ }^{163}$ University of Novi Sad, Faculty of Economics Subotica, Segedinski put 9-11, Subotica, Serbia

164 JKP Informatika Novi Sad, Bulevar cara Lazara 3, Novi Sad, Serbia

${ }^{165}$ University of Novi Sad, Faculty of Economics Subotica, Segedinski put 9-11, Subotica, Serbia
} 
from large Venture Capital (VC) investments, in order to determine the real nature of Initial Coin Offerings (ICO's). Companies doing the ICO process usually rely on Ethereum blockchain to create ERC20 compatible tokens built upon Ethereum network. These tokens use decentralized network and ETH20 compatible wallets to circulate. There are no formal requirements for holding an ICO as stated - a company making an ICO decides what and how your token holders will get in exchange for their money. Therefore in the ICO process company determines and markets the token properties in order to attract the investors, unless stated and manifested explicitly tokens do not hold any equity value. Because of this, the research suggests that "the nature of ICO is a quick buy-sell process. So, most of the investors will look to sell the tokens for a quick profit and will drop your project if it's struggling with some issues without sentiments". When investing, investors send Ethereum - ETH to the predefined smart contract address, in order to get tokens in return for their investment. Since Blockchain provides full transparency, all transactions can be tracked and analyzed. Research used a web application called ETHERSCAN [1] to see the data of various ICO smart contracts addressed for the time of ICO phase to analyze the number of investors, invested amounts and to compare invested amounts to the total raised funds in order to gain insight into the nature of the ICO investment process.

\section{THEORETICAL FRAMEWORK OF THE RESEARCH}

\subsection{THEORETICAL DISTINCTION BETWEEN ICO AND VC}

In terms of financial market $\mathrm{VC}$ is a well-known funding source. When acquiring funding from venture capitalist, a company offers company equity in exchange for funding. A venture capitalist is willing to take the risk in exchange for the equity. In contrast to VC funding, ICO is a process of raising money worldwide from anyone having Internet and enough money to buy a token. "Token is a unit of value issued by a tech or crypto start-up, intended to be a piece in the ecosystem of their technology, platform or project. Tokens are supported by blockchains. They only physically exist in the form of registry entries in the said blockchain. Initially, most tokens were based on the ERC20 protocol by Ethereum" [2].

ICO is an invention allowing startups to fund themselves by using crowdfunding as a funding source without any legal or equity commitment. Another quality of is community engagement since ICO is a process of quick money rising with as many people involved as possible. These participants in the ICO later become token holders and they are interested in further development of the project because of the potential usage or token price increase. This creates a strong and engaged community for startup. Startups that require a lot of potential consumers and marketing reach should, therefore, favor the ICO instead of valuable individuals that they can reach with VC. The easiest way to distinguish the audiences between ICO and VC is to compare ICO to business to consumer sales and VC to business to business sales. VC investors are experienced businessmen with their own views and demands. They often require a formal review of the demo, white papers, smooth pitch, detailed roadmap, etc. VC requires far more preparations than in ICO case. On other hand, VC investors are much more reliable, they are willing to support your project for a long time and are not looking for a quick return on their investment. There are other tangible and intangible benefits that can be gained from VC additional to the funding. A venture capitalist can also provide startups with their network of connections to the industry influencers, business guidelines, proof of concept, consulting, easier access to resources, testing ground, etc. 
ICO's can be distincted from VC based on requirements, geography and accessibility and public perception. VC requires strong staff, working product or demo, vision, well-prepared pitch, plan, documentation, etc. Also, once you have a deal, you need to share a part of your company equity. On the other hand, there are no formal requirements for holding an ICO. The company is free to decide what and how your token holders will get in exchange for their investment. In terms of geography, VC investors are solid and conservative. Usually, they strongly prefer companies in the same country. They want you to come to numerous meetings and sign numerous papers. ICO's are not limited by geography in any aspect. In terms of public perception, $\mathrm{VC}$ has a strong advantage. Rising money from VC gives you a strong credibility, credit, and PR since VC's are much more sophisticated and check the project comprehensively before investing. In the case of ICO - the company is going public for the first time.

\section{Benefits of VC}

- Investors Trustworthiness;

- Business advice and information support;

- Building valued contacts;

- PR recognition.

\section{Benefits of ICO}

- No equity required;

- No working product required;

- No geographic limitations;

- Rapidity - no bureaucracy or other legislation.

Table 1: Venture Capital and ICO

\begin{tabular}{|l|l|l|}
\hline Team & \multicolumn{1}{|c|}{ Venture } & \multicolumn{1}{c|}{ ICO } \\
A mix of technology and & $\begin{array}{l}\text { Track record in crypto } \\
\text { currency community } \\
\text { Highly technical }\end{array}$ \\
\hline Market & $\begin{array}{l}\text { Large \$1B+ addressable } \\
\text { market, potential pivots }\end{array}$ & $\begin{array}{l}\text { Predefined large technical } \\
\text { problem } \\
\text { Proximity to infrastructure }\end{array}$ \\
\hline Traction & $\begin{array}{l}\text { MVP or initially committed } \\
\text { customers }\end{array}$ & $\begin{array}{l}\text { Prior technical projects } \\
\text { publicly shared on Github }\end{array}$ \\
\hline Competition & $\begin{array}{l}\text { Structure of industry } \\
\text { meaningful for the ability to } \\
\text { monopolize position }\end{array}$ & $\begin{array}{l}\text { Many blue-ocean } \\
\text { opportunities need an only } \\
\text { vague market strategy }\end{array}$ \\
\hline Economics \& Distribution & $\begin{array}{l}\text { Business model exists and } \\
\text { works on the margin }\end{array}$ & $\begin{array}{l}\text { Vague indication tends to be } \\
\text { sufficient }\end{array}$ \\
\hline Legal Status & $\begin{array}{l}\text { Well defined C-Corp or } \\
\text { SAFE investments }\end{array}$ & $\begin{array}{l}\text { A wide range of legality, } \\
\text { from CoinList to frauds and } \\
\text { scams }\end{array}$ \\
\hline Presentation & $\begin{array}{l}\text { PowerPoint, Demo } \\
\text { Relationship drove }\end{array}$ & $\begin{array}{l}\text { Tech whitepaper, video } \\
\text { Highly social media }\end{array}$ \\
\hline
\end{tabular}

(Source: https://next.autonomous.com/) 


\subsection{SUSPECTED INFLUX OF VC INTO ICO'S}

Despite the rising alarms coming from regulatory bodies over the ICOs, venture capitalists have revealed growing interest in these offerings. However, what they are more interested in is the equity stakes rather than the profits from coin trades. Statistics that the funding has increased vividly in the blockchain based firms and startups have managed to raise more than about $\$ 430$ million in the first quarter of 2018. According to the statistics by TokenData, in 2017, 46 percent of the token startups either suffered from fiasco after the offering or could not complete funding. So far in 2018, a total of 50 startups have failed out of 340 . It is very obvious why the failure rate is so high - ICO's were not planed property, many of the products they are offering are not even functional - the technology has not even been tested on a mass scale, etc. [3]. Investors are interested in the acquisition of security tokens with some kind of security attached in the form of equity or other to mitigate risk in case there is some kind of regulatory surprise in the future. With further regulation of ICO market and reducement of black chain market volatility (which is still highly volatile), VC interest in blockchain and ICO is generally rising. VC are increasing their investments in ICO's and hold large portions of issued tokens.

In order to examine the concentration of token holders this research used etherscan.io to see the related addresses for more than 20 examined ICO's in 2017.

Table 2: The statistics by TokenData

\begin{tabular}{|l|c|c|c|}
\hline \multicolumn{1}{|c|}{2017.} & $\begin{array}{c}\text { Top 10 addresses } \\
\text { (more than) } \%\end{array}$ & $\begin{array}{c}\text { Following } 90 \text { addresses } \\
\text { (more than) } \%\end{array}$ & $\begin{array}{c}\text { Remaining } \\
\text { Addresses }\end{array}$ \\
\hline January & 50 & 22 & 28 \\
\hline February & 53 & 20 & 27 \\
\hline March & 55 & 10 & 35 \\
\hline April & 43 & 17 & 40 \\
\hline May & 49 & 23 & 28 \\
\hline Jun & 45 & 14 & 41 \\
\hline July & 44 & 24 & 32 \\
\hline August & 41 & 17 & 42 \\
\hline September & 51 & 20 & 29 \\
\hline October & 49 & 22 & 29 \\
\hline November & 44 & 12 & 44 \\
\hline December & 39 & 17 & 34.92 \\
\hline AVG. & 46.92 & 18.17 & \\
\hline
\end{tabular}

(Source: https://www.tokendata.io)

It is critical to take into consideration the following limitations to this type of research and gathering of the data [4], [5]:

- Columns represent ownership of the address band, first 10, following 90, then the rest.

- Actually, a number of holders may be even smaller because 1 holder can have multiple addresses.

- It is accepted a practice that company that is issuing tokens may hold a number of tokens for themselves or award the development team with a $\%$ or an absolute number of tokens for the development efforts. Because of this practice, concentration of tokens in the largest 10 holders is partially caused by the issuing company own stock or reserve so to call it and not necessarily held by VC investors. 
- Not all data for all ICO's is gathered due to the number of individual investments and nature of smart contract programming so data can be considered as preliminary data.

\section{CONCLUSION AND FURTHER STUDY}

Further study should attempt to discover the percentage of token held by a development company and take this data into consideration as well as completely acquire all blockchain transactions for each ICO's in order to have complete data for analysis. The area of study of $\mathrm{VC}$ is highly interesting and may show a completely different market mechanic and marketing approach for this new and emerging market that may hold more than trillion dollars in the next decade.

The research may imply the hypothesis that ICO'S investment allocation shows Pareto distribution. In order to check this hypothesis, complete analysis of all ICO'S for some time period should be gathered and data should be analyzed with taking into consideration the token percentages supposedly held by issuing company. Furthermore - token addresses held by the company may also contain tokens owned by some hidden VC investors that have an offblockchain agreement with the company so reserve has to be expressed.

Two additional phenomena may guide the conclusion that the $\mathrm{VC}$ is beginning to conquer and dominate ICO market which should, by its definition, be structured as a crowdfunding market. It is increased regulatory and government pressure and token type trend. Equity and security tokens are strongly replacing utility tokens in 2018, which may point to startup company realization of growing VC influx into ICO market as an attempt to improve their product marketing performance. A similar question can be drawn in parallel to the regular market: what is the product of a company- it's stock or a product of its economic activity? In ICO market it is hard to differentiate is the end product a token or is it merely a vessel to fund or facilitate some other product?

\section{REFERENCES}

[1] www.etherscan.io

[2] https://next.autonomous.com/

[3] https://www.tokendata.io/

[4] D'Ambrosio, M., Gianfrate, G. (2016) Crowdfunding and Venture Capital: Substitutes or Complements?, The Journal of Private Equity Vol. 20, No. 1 (WINTER 2016), pp. 7-20.

[5] https://www.crowdfundinsider.com/2014/07/43648-real-difference-vc-crowdfundinginvestment-marketing/ 